\title{
Autonomous Traffic System for Emergency Vehicles
}

\author{
Mamoona Humayun ${ }^{1, *(D)}$, Maram Fahhad Almufareh ${ }^{1}$ and Noor Zaman Jhanjhi ${ }^{2}$ (D) \\ 1 Department of Information Systems, College of Computer and Information Sciences, Jouf University, \\ Sakakah 72388, Saudi Arabia; mfalmufareh@ju.edu.sa \\ 2 School of Computer Science and Engineering (SCE), Taylor's University, Subang Jaya 47500, Malaysia; \\ noorzaman.jhanjhi@taylors.edu.my \\ * Correspondence: mahumayun@ju.edu.sa
}

check for updates

Citation: Humayun, M.; Almufareh, M.F.; Jhanjhi, N.Z. Autonomous Traffic System for Emergency Vehicles. Electronics 2022, 11, 510. https://doi.org/10.3390/

electronics 11040510

Academic Editor: Arturo de la Escalera Hueso

Received: 6 January 2022

Accepted: 4 February 2022

Published: 9 February 2022

Publisher's Note: MDPI stays neutral with regard to jurisdictional claims in published maps and institutional affiliations.

Copyright: (c) 2022 by the authors. Licensee MDPI, Basel, Switzerland. This article is an open access article distributed under the terms and conditions of the Creative Commons Attribution (CC BY) license (https:// creativecommons.org/licenses/by/ $4.0 /)$.

\begin{abstract}
An emergency can occur at any time. To overcome that emergency efficiently, we require seamless movement on the road to approach the destination within a limited time by using an Emergency Vehicle (EV). This paper proposes an emergency vehicle management solution (EVMS) to determine an efficient vehicle-passing sequence that allows the EV to cross a junction without any delay. The proposed system passes the EV and minimally affects the travel times of other vehicles on the junction. In the presence of an EV in the communication range, the proposed system prioritizes the EV by creating space for it in the lane adjacent to the shoulder lane. The shoulder lane is a lane that cyclists and motorcyclists will use in normal situations. However, when an EV enters the communication range, traffic from the adjacent lane will move to the shoulder lane. As the number of vehicles on the road increases rapidly, crossing the EV in the shortest possible time is crucial. The EVMS and algorithms are presented in this study to find the optimal vehicle sequence that gives EVs the highest priority. The proposed solution uses cutting-edge technologies (IoT Sensors, GPS, 5G, and Cloud computing) to collect and pass EVs' information to the Roadside Units (RSU). The proposed solution was evaluated through mathematical modeling. The results show that the EVMS can reduce the travel times of EVs significantly without causing any performance degradation of normal vehicles.
\end{abstract}

Keywords: emergency vehicles; shoulder lane; IoT; cloud computing; 5G; roadside unit

\section{Introduction}

Roads have grown increasingly crowded in the last few decades due to the rapid increase in population. Excessive traffic has created many problems such as property damage, air pollution, time wastage, and loss of life due to accidents. Careful city planning can alleviate transportation problems, but planning does not always function effectively in the face of unforeseen population and vehicle usage development [1]. Various intelligent traffic control systems have been introduced in the past few years to better manage and control rapidly increasing traffic [2]. However, passing EVs in peak traffic hours is a challenge that needs to be addressed. An EV is a vehicle that provides emergency services in an incident. These vehicles are usually exempted from conventional traffic rules to reach their destination as soon as possible. EVs are mainly categorized into three types: medical, firefighting, and law enforcement. These EVs are equipped with audible and visual warning devices that help them reach their destination as soon as possible [3,4].

Different countries have developed various intelligent systems for passing EVs without disrupting the other traffic. These systems use Global Positioning Systems (GPS), ComputerAided Dispatch (CAD), and traffic management information to determine the location of EVs and the estimated time of reaching the junction. These systems automatically turn red lights into green until EVs cross that intersection; once an EV passes the intersection, the traffic lights operate in a normal mode to minimize traffic disruptions $[5,6]$. These systems pass the EV in normal situations when the road is not congested and there is only 
a single $\mathrm{EV}$, but what if the road is highly congested and there is no space for the other vehicles to change lanes? Or if more than one EV is coming from opposite directions of the signal? In addition, the criticality level of all emergencies is not the same. Therefore, a proper mechanism is required that may pass multiple EVs arriving at an intersection simultaneously with minimum delay through EV scheduling.

EVs are usually at high speed. Therefore, there is a great chance of crashes occurring if there is congestion on the road. A key motivation behind the EV scheduling and management mechanism is to reduce EV crashes. According to the statistics provided by National Safety Council (NSC) [7], the US experienced 170 deaths in 2019 which involved EVs. The vast majority (63\%) of those killed were passengers in non-emergency vehicles. Figure 1 provides the statistics for the last seven years. These statistics show that most of the fatalities occurred in multiple-vehicle crashes. Most deaths were caused by incidents involving law enforcement vehicles 114, followed by ambulances 33, and fire trucks 28 . According to paper [8], when ambulances run with lights and sirens, there is a possibility for an increase in collision risk. The collision rate is 4.6 per 100,000 replies when an ambulance responds to an emergency call without lights and sirens. When lights and sirens are employed, the accident rate rises to 5.5. When the ambulance is transporting a person, the risk is significantly higher. Without lights and sirens, the accident risk is 7.0 per 100,000 transports; however, when lights and sirens are employed during the trip, the risk rises to 16.5 per 100,000 transports. To reduce these fatalities and improve passengers' security on the road, there is a need to develop a system that may overcome the existing problems associated with the passing of EVs.

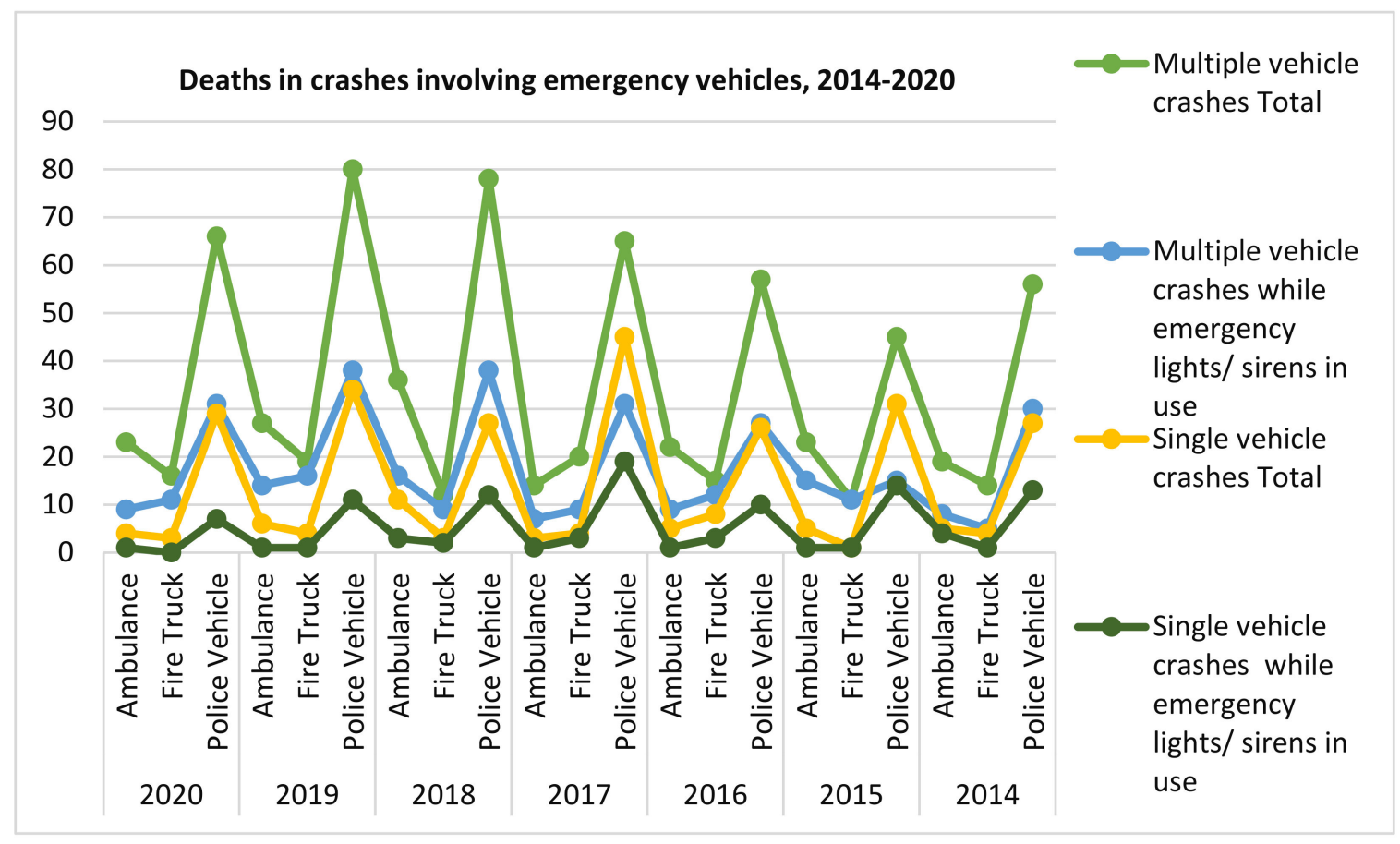

Figure 1. Death statistics of crashes involving EVs [7].

This paper provides a solution for passing EVs in various situations. The EV in the proposed system is an intelligent vehicle that can sense its surroundings with minimum human interference. EVs are prioritized based on their criticality, and this information is stored on the cloud which is accessible to RSU. When multiple EVs arrive at the intersection simultaneously, the decision is based on the priority of the EV. If both vehicles with the same priority reach the intersection simultaneously, the proposed system calculates the distance between $\mathrm{EV}$ and destination and gives priority to the EV with more distance. To 
pass EVs in congestion, a shoulder lane will be used to move vehicles to vacate EV space. Thus, the proposed solution provides a significant contribution, as follows:

- Explore the existing traffic management strategies and find the gaps for routing EV, as described in Section 2.

- Prioritize EVs based on their criticality, propose a model for passing single and multiple EVs based on priority and distance, and propose multiple algorithms for passing EVs with the same priority and varying priority; all this is discussed in Section 3.

- Mathematical modeling of the proposed system is provided in Section 4.

- Evaluating the model and algorithms mathematically is in Section 5.

Before moving towards the proposed solution, we provide insights into existing solutions for managing EVs and for identifying the existing gaps in the next section. Table 1 provides the list of abbreviations used in this research paper for a better understanding.

Table 1. List of abbreviations used in this study.

\begin{tabular}{llll}
\hline Abbreviations & Used for & Abbreviations & Used for \\
\hline EVMS & Emergency vehicle management & DICA & DTOT-based Intersection Control \\
EV & Algorithm \\
RSU & Emergency vehicle & DTOT & Discrete-Time Occupancies Trajectory \\
CAD & Roadside unit & TMC & Traffic Management Center \\
GPS & Computer aided dispatch & ITS & Intelligent traffic system \\
NSC & Global positioning system & EVPS \\
RFID & national safety council & IoT & Emergency Vehicle Priority System \\
SUMO & Radio Frequency Identification & PLC & Internet of Things \\
BFMG & Simulation of Urban Mobility & TLS & Programmable Logic Controller \\
DSRC & Budget and Financial Management & SL & Traffic Light Systems \\
ED & Guidance & OBUs & Shoulder Lane \\
CD & Dedicated short-range communications & MD & On-board units \\
\hline
\end{tabular}

\section{Literature Review}

This section explores the existing traffic management strategies for routing EVs and provides a comparative analysis of these studies to identify the possible research gaps related to traffic management based on traffic accidents.

In paper [5], an evolutionary method is suggested to handle the optimization issue of finding the ideal vehicle sequence that provides precedence to EVs. Comparisons with the DTOT-based Intersection Control Algorithm (DICA) and a reactive traffic signal algorithm and comprehensive simulations are used to verify the effectiveness of the suggested technique for expediting EVs' crossings. There is no discernible impact on regular vehicle performance from the suggested genetic algorithm, which dramatically reduces the journey durations of EVs in light and medium traffic loads without degrading their performance.

When an EV approaches a junction, a Radio Frequency Identification (RFID)-based system is suggested, as in paper [9], to monitor and regulate traffic signals so that the vehicle may easily exit the traffic jam and go to its destination. An experimental setup utilizing Arduino and light-emitting diode (LED) displays was chosen to mimic a realworld traffic situation to test the suggested framework. Simulated findings show that the authors' EV detection and management framework performs better than the current system in peak hours.

Paper [10] presents a method for scheduling EVs in traffic. The technology integrates optical sensing, vehicle counting, and time-sensitive warning transmission inside the sensor network to calculate the distance between EVs and junctions. An EV and intersection are measured with visual data and compared using Euclidean, Manhattan, and Canberra approaches. There is evidence that the Euclidean distance is superior to other distance measuring methods and may be used in real-time. 
Usually, the department establishes a target travel time for an EV, but it is difficult to meet in most cases. Study [11] proposes a novel Intelligent Traffic System (ITS) that takes into account the priorities of EVs depending on the kind of event and a mechanism for detecting and reacting to traffic signal hacking to address this problem directly. A simulation experiment was carried out. For EVs, this system outperforms both already operating and newly planned ITS in terms of congestion avoidance and trip time savings. Budget and Financial Management Guidance (BFMG)'s reaction time objective for both conventional and hacked traffic lights is met by the proposed method.

Based on the kind and severity of an event, paper [12] introduces an Emergency Vehicle Priority System (EVPS) that determines an EV's priority based on its type and severity and estimates the number of required signal interventions while taking into account their influence on traffic on nearby roads. A novel technique to estimate the number of green signal interventions needed to achieve the fastest incident response time while also minimizing the effect on others is presented, along with an explanation of how EVPS arrives at the priority code. Simulation of Urban Mobility (SUMO) uses actual traffic data from sensors in Melbourne, Australia to create a simulation model. The proposed system's findings suggest that implementing the recommended number of interventions may dramatically shorten its time to respond to an emergency. Paper [13] proposes a novel way for managing EV traffic using the Internet of Things (IoT). With the traffic signal controller positioned at a junction, EVs may notify it about arrival to manage traffic. The EV's passengers must utilize the Android app installed on their phones to communicate with the traffic controller hardware. A cutting-edge approach is also suggested in this paper for automatically managing traffic.

An automated traffic management system with EV control is the focus of paper [14]. In the event of an emergency signal, the system automatically maintains the condition of the regular sequence. It provides the associated route a green light signal for the duration of the signal. When the emergency signal is no longer strong enough, the system immediately returns to the previously saved condition of the usual sequence. RFID technology is used to identify emergency signals. Programmable Logic Controller (PLC) ladder logic is used to create the system. PLC simulation was used to implement the system. After that, it was put to the test in a working prototype of the hardware. The results of the tests showed that the original code does not need to be altered to make it work in the real world. This PLC-based system may replace the standard traffic control system. A complete city's traffic system may be dynamically managed using a PLC system with extra input and output modules.

An IoT-based platform for EV priority and self-organized traffic control at crossings is presented in the article [15]. A new platform and protocol known as EVP-STC is proposed, which consists of three basic components. First, the junction controller, which is mounted at traffic signals, gathers EV location data and vehicle density data on each road segment approaching an intersection. Based on this real-time traffic data, the junction controller subsequently makes adjustments to the timing of the traffic lights. A second system with force resistive sensors is put at each road section to identify automobiles. ZigBee is used to communicate with the intersection controller to send the information it has detected. EVs are equipped with a third system that gives the junction controller with GPS coordinates so that emergency vehicles do not have to wait at intersections. The simulation results show the proposed platform's ability to reduce overall delays, lane opening times, and waiting times for emergency vehicles.

Paper [16] claims that a variety of options for dealing with EVs have been proposed, including special lanes for EVs in cities. However, EVs sometimes find it difficult to meet their optimal goal timings even with these lanes. Existing technology may be used in conjunction with present infrastructure to create an ITS that can assist in tackling this issue. TLS, RFID, and IoT are compared in this research. According to the study's findings, using IoT, data on traffic congestion may be gathered more rapidly and correctly. A "User Interface" for mobile applications may be used to identify congestion in various locations, as well as give users other paths. These strategies are designed to provide drivers with 
more information about traffic and road conditions so that they may make better-informed decisions. Through ITS, EVs may be given precedence over non-emergency cars.

Paper [17] proposes a way to alleviate transportation congestion in a smart city environment. According to the proposed solution, every junction of the road should have a sensor node and a camera installed to collect real-time traffic data. Central servers may be used for a variety of purposes, including storing traffic data and providing high-priority vehicles with updates on their status and the best possible alternative routes to avoid traffic jams in real-time.

The foregoing discussion and analysis of other current research, such as [4,18-21], reveal that passing EVs at intersections is a major difficulty, particularly in crowded metropolitan locations. Table 2 compares prior research to understand the gaps better. Researchers and practitioners have offered a variety of remedies, yet the issue persists. In the next section, an autonomous traffic management system for EVs is offered as a solution to this problem.

Table 2. Research Gap based on Literature.

\begin{tabular}{|c|c|c|c|c|c|}
\hline Pap\# & $\begin{array}{l}\text { Problem } \\
\text { Discussed }\end{array}$ & $\begin{array}{l}\text { Proposed } \\
\text { Solution }\end{array}$ & $\begin{array}{l}\text { Technology } \\
\text { Used }\end{array}$ & Contribution & Research Gap \\
\hline$[5]$ & $\begin{array}{l}\text { EV crossing at the } \\
\text { intersection }\end{array}$ & Reactive DICA & $\begin{array}{l}\text { Genetic } \\
\text { algorithm }\end{array}$ & $\begin{array}{l}\text { Optimize the sequence of } \\
\text { vehicles } \\
\text { reducing travel times of EVs } \\
\text { minimal effect on the } \\
\text { performance for normal } \\
\text { vehicles }\end{array}$ & $\begin{array}{l}\text { Only address } \\
\text { autonomous vehicles }\end{array}$ \\
\hline [9] & $\begin{array}{l}\text { EV crossing at } \\
\text { peak hours }\end{array}$ & $\begin{array}{l}\text { Emergency vehicle } \\
\text { detection and } \\
\text { management } \\
\text { framework }\end{array}$ & $\begin{array}{l}\text { RFID-based } \\
\text { system }\end{array}$ & $\begin{array}{l}\text { Better performance in detection } \\
\text { as well as management of } \\
\text { emergency vehicle }\end{array}$ & $\begin{array}{l}\text { The Lane clearing } \\
\text { process in case of } \\
\text { congestion is not } \\
\text { discussed }\end{array}$ \\
\hline [10] & $\begin{array}{l}\text { Distance measure } \\
\text { of EV from the } \\
\text { intersection }\end{array}$ & $\begin{array}{c}\text { Visual sensing } \\
\text { techniques } \\
\text { developed VANET } \\
\text { model }\end{array}$ & $\begin{array}{l}\text { PE-MAC } \\
\text { protocol, } \\
\text { NS-2 }\end{array}$ & $\begin{array}{c}\text { Emergency vehicle information } \\
\text { is measured accurately, } \\
\text { the measured information is } \\
\text { delivered to the TMC in less } \\
\text { time }\end{array}$ & $\begin{array}{l}\text { Distance measurement } \\
\text { in bad weather and } \\
\text { high traffic conditions }\end{array}$ \\
\hline [11] & $\begin{array}{l}\text { Meeting the target } \\
\text { travel time of an } \\
\text { EV }\end{array}$ & $\begin{array}{l}\text { An Intelligent } \\
\text { Traffic Signal } \\
\text { system }\end{array}$ & IoT & $\begin{array}{l}\text { Meet the target travel time of an } \\
\text { emergency vehicle set by the } \\
\text { Department }\end{array}$ & $\begin{array}{l}\text { Do not discuss the } \\
\text { normal traffic flow and } \\
\text { the process of vacating } \\
\text { lane for EV }\end{array}$ \\
\hline [12] & $\begin{array}{l}\text { Sending EV } \\
\text { quicker to the } \\
\text { incident place }\end{array}$ & EVPS & SUMO & $\begin{array}{l}\text { Recommend an appropriate } \\
\text { intervention number that assists } \\
\text { an EV in reducing response time }\end{array}$ & $\begin{array}{l}\text { Do not discuss the } \\
\text { process of vacating } \\
\text { lane for EV }\end{array}$ \\
\hline [13] & $\begin{array}{l}\text { Better } \\
\text { management of EV } \\
\text { traffic }\end{array}$ & Prototype & IoT & $\begin{array}{l}\text { Management of EV in an } \\
\text { effective way }\end{array}$ & $\begin{array}{c}\text { Do not discuss the } \\
\text { normal traffic flow and } \\
\text { the process of vacating } \\
\text { lane for EV }\end{array}$ \\
\hline [14] & $\begin{array}{l}\text { Emergency } \\
\text { Vehicle Detection } \\
\text { and Management }\end{array}$ & Prototype & $\begin{array}{l}\text { RFID, } \\
\text { High Priority } \\
\text { Encoder }\end{array}$ & $\begin{array}{l}\text { Emergency Vehicle Detection } \\
\text { and Management system }\end{array}$ & $\begin{array}{l}\text { Validation in a real } \\
\text { setting is missing, } \\
\text { Do not discuss the } \\
\text { process of vacating } \\
\text { lane for EV }\end{array}$ \\
\hline [15] & $\begin{array}{l}\text { EV priority and } \\
\text { self-organized } \\
\text { traffic control }\end{array}$ & EVP-STC protocol & $\begin{array}{l}\text { IoT } \\
\text { Zigbee } \\
\text { GPS }\end{array}$ & $\begin{array}{l}\text { EVs do not have to wait at } \\
\text { intersectionsreduce overall } \\
\text { delays, lane opening times, and } \\
\text { waiting times for emergency } \\
\text { vehicles }\end{array}$ & $\begin{array}{l}\text { Do not discuss the } \\
\text { normal traffic flow and } \\
\text { the process of vacating } \\
\text { lane for EV during } \\
\text { congestion }\end{array}$ \\
\hline
\end{tabular}


Table 2. Cont.

\begin{tabular}{|c|c|c|c|c|c|}
\hline Pap\# & $\begin{array}{l}\text { Problem } \\
\text { Discussed }\end{array}$ & $\begin{array}{l}\text { Proposed } \\
\text { Solution }\end{array}$ & $\begin{array}{l}\text { Technology } \\
\text { Used }\end{array}$ & Contribution & Research Gap \\
\hline [16] & $\begin{array}{c}\text { Traffic } \\
\text { management }\end{array}$ & $\begin{array}{l}\text { Review of existing } \\
\text { technologies used } \\
\text { in ITS }\end{array}$ & $\begin{array}{l}\text { RFID tag, } \\
\text { magnetic } \\
\text { sensor, IR } \\
\text { sensor, WSN, } \\
\text { IoT, etc. }\end{array}$ & $\begin{array}{l}\text { Provide the comparison of } \\
\text { existing ITS along with their } \\
\text { pros and cons }\end{array}$ & $\begin{array}{l}\text { Only suggestions are } \\
\text { mentioned without } \\
\text { validation }\end{array}$ \\
\hline [17] & $\begin{array}{c}\text { Congestion } \\
\text { handling and } \\
\text { controlling of EVs }\end{array}$ & $\begin{array}{l}\text { The idea of a } \\
\text { self-configurable } \\
\text { system is proposed }\end{array}$ & $\begin{array}{l}\text { PIC microcon- } \\
\text { troller, RF } \\
\text { transceiver, } \\
\text { ultrasonic } \\
\text { sensors }\end{array}$ & $\begin{array}{l}\text { Provide the comparison of } \\
\text { existing ITS along with their } \\
\text { pros and cons, } \\
\text { The idea of a self-configurable } \\
\text { system is proposed }\end{array}$ & Validation is missing \\
\hline
\end{tabular}

\section{Proposed Methodology}

In major cities, traffic congestion is a problem, and EVs have to contend with it as well. For the sake of preserving human life, a delay in the arrival of an EV is sometimes unavoidable. To address this issue, we propose a solution named EVMS, as illustrated in Figure 2.

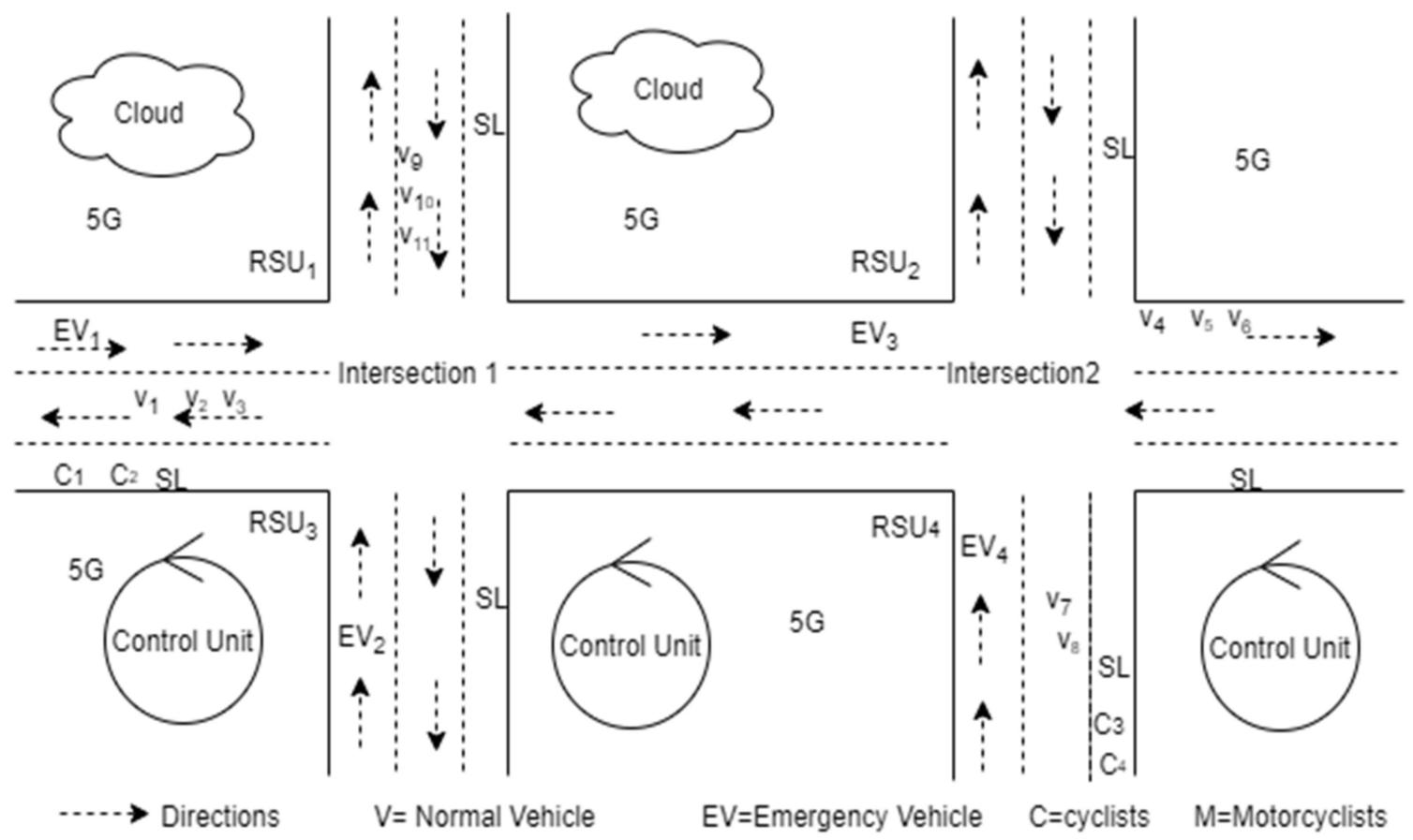

Figure 2. An overview of EVMS.

\subsection{Components of the EVMS}

The proposed EVMS consists of seven components along with priority rules. The details of these components are discussed in the following.

\subsubsection{Emergency Vehicle (EV)}

An EV is a vehicle that emergency personnel use to react to a situation. These vehicles are normally run by recognized agencies, which are often government entities, but they may also be non-governmental groups or commercial firms that have been specially authorized by legislation [22]. To get to their destinations as quickly as possible, EVs may be excluded from several standard road restrictions, such as passing through a junction while the traffic 
signal is red or exceeding the speed limit. We categorize EVs into three groups in our suggested solution: medical, firefighting, and law enforcement [23]. The EVs in the EVMS are equipped with IoT sensors that collect real-time data of EVs and transmit it to the cloud using 5G.

\subsubsection{Shoulder Lane (SL)}

In the proposed system, every crowded road has an SL that is reserved for cyclists and motorcyclists in normal situations. In the case of an EV entering the intersection range, the lane adjacent to the SL is shifted towards the SL to make room for the EV. The SL is narrower than other lanes [24]. The benefits of having an SL are many [25]: first, cyclists and motorcyclists may quickly move to the pavement or other lanes in case of EV arrival. Secondly, the separate lane for cyclists and motorcyclists will help in reducing congestion in the other lanes. Third, the EV can pass through the intersection even during congestion.

\subsubsection{Roadside Unit (RSU)}

An RSU is a Dedicated Short-Range Communications (DSRC) transmitter that is attached to a roadway or pedestrian walkway. Any vehicle or hand-carried unit may have an RSU attached to it; however, the RSU can only work while the vehicle or hand-carried unit is at a standstill. In addition, an RSU operating under this section is limited to the area in which it has been granted a license to do so [26,27]. RSUs that are small enough to be carried around and not interfere with a fixed installation are allowed to function. For example, an RSU transmits or exchanges data with other Onboard units (OBUs) in its communications area through radio waves. OBUs in an RSU's communications zone may also request channel allocations and operational instructions from the RSU. In the EVMS, RSUs will be used by the control unit to manually interfere with traffic signals when there is an EV on the road [26,28]. It will gather traffic data from a static sensing region along a road and communicate it to traffic control devices and a central traffic management center [28].

\subsubsection{Control Unit}

The control unit in the EVMS collects vehicle information from the cloud and takes action accordingly. It is responsible for managing road traffic, pedestrian traffic, and EVs on the road.

\subsubsection{IoT}

Connected physical items (or groups of such objects) with sensors, computing power, software, and other technologies that exchange data via the Internet or other communications networks are known as IoT [19,29]. In the EVMS, these IoT sensors are embedded in the EV for the collection of real-time data, and they transmit it on the cloud using $5 \mathrm{G}$ from where the control unit accesses it to take decisions.

\subsubsection{Cloud}

IoT devices attached/embedded in EVs generate a huge amount of real-time data, the cloud is used for the storage of this data [30,31] that can be further used for decision making. The EVMS uses the public cloud for storing EV information, road traffic, and other related data.

\subsection{7. $5 \mathrm{G}$}

As the name suggests, $5 \mathrm{G}$ refers to the next generation of mobile networks, which will be able to provide consumers with faster peak data speeds, ultra-low latency, greater dependability, huge network capacity, better availability, and a more consistent user experience $[32,33]$. The proposed system leverages the benefits of $5 \mathrm{G}$ and uses it for data transmission between IoT devices and the cloud, and from the cloud to control units. 


\subsubsection{Priority Rules}

EVs are of different types and have various levels of emergency. In the EVMS, medical vehicles have the highest priority [34], then comes the firefighting vehicles, followed by law-enforcement vehicles. Medical EVs (MEVs) are further categorized into three levels named as: critical, less critical, and moderate. A critical EV is one which carries a critical patient, a less critical medical EV is one which moves a less critical patient (such as a delivery case, etc.) from one place to another, while a moderate EV is one that is empty or carries a dead body or medical equipment that are not so urgent. The firefighting EVs (FEVs) and law enforcement EVs (LEVs) will have only one priority that is a high priority. Equations (1) and (2) show the priority of the three types of EVs.

If a medical EV is critical or less critical, then the priority will be as shown in Equation (1).

$$
P(\mathrm{MEV})>P(\mathrm{FEV})>P(\mathrm{LEV})
$$

If a medical EV is moderate, then the priority of EVs will be as shown in Equation (2).

$$
P(\mathrm{FEV})>P(\mathrm{LEV})>P(\mathrm{MEV})
$$

where MEV represents medical EV, FEV represents firefighting EV, and LEV represents law enforcement EV.

\subsection{Working Mechanism of EVMS}

The roads which are usually congested in peak hours will have a shoulder lane for traffic adjustment in case of EVs on the road. When any EVs approach the junction, the data of that EV (EV number, destination, priority, velocity, speed) will be sent to the cloud through IoT sensors using 5G Internet service. The control unit will fetch the data from the cloud and will come to know about the details of the EV; if there is only one EV on the road, the normal traffic on the road will move to the SL and space will be vacated for the EV to move towards the junction. The control unit will turn red lights into green lights until the EV passes the junction successfully. Once the EV passes the junction, the traffic signal will operate normally. If two EVs are coming from varying directions, the decision of passing the EV through the junction will be decided based on the priority of the EVs as mentioned in Equations (1) and (2). If both EVs with the same priority are coming from varying directions, the control unit will give priority to the EV that is further from its destination. If two EVs are coming from varying directions but their priority is different, then the vehicle with high priority will be given preference according to Equations (1) or (2). Algorithms 1 and 2 show the working of a proposed approach.

Algorithm 1 shows the working of the EVMS in the case of 1 or more EVs, while Algorithm 2 shows how medical EVs with varying priorities will be passed through the junction. As mentioned in the description of priority rules, MEVs have three priorities named critical, less critical, and moderate. Algorithm 2 shows the process of passing EVs with varying priorities of MEVs

Case 1 of Algorithm 1 is modeled in Figure 3, where two MEVs are coming from different directions in such a way that the signal of both sides cannot be green at the same time. Further, both EVs have the same priorities; in such a situation, the EV with more distance from its destination will be given priority. 


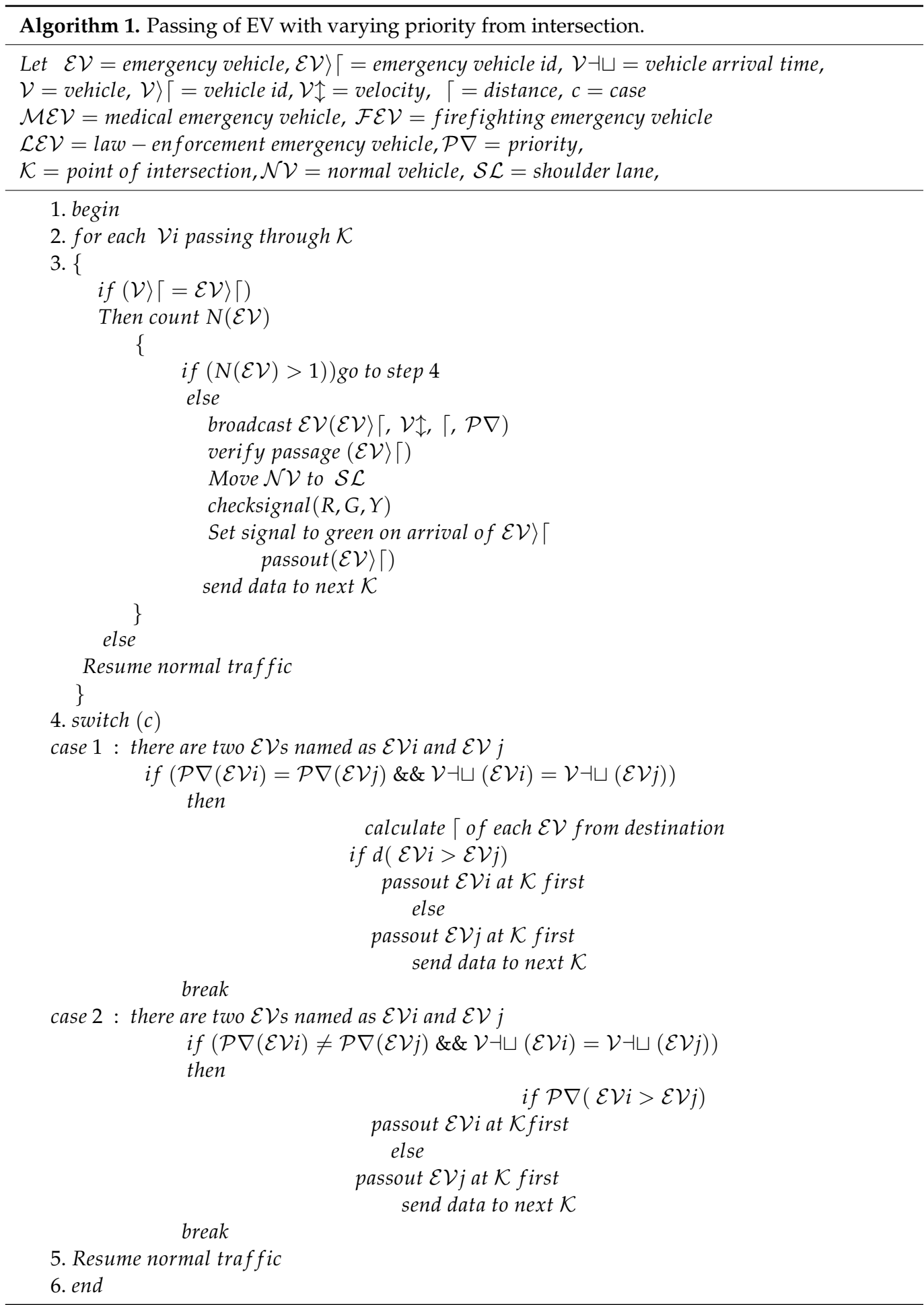




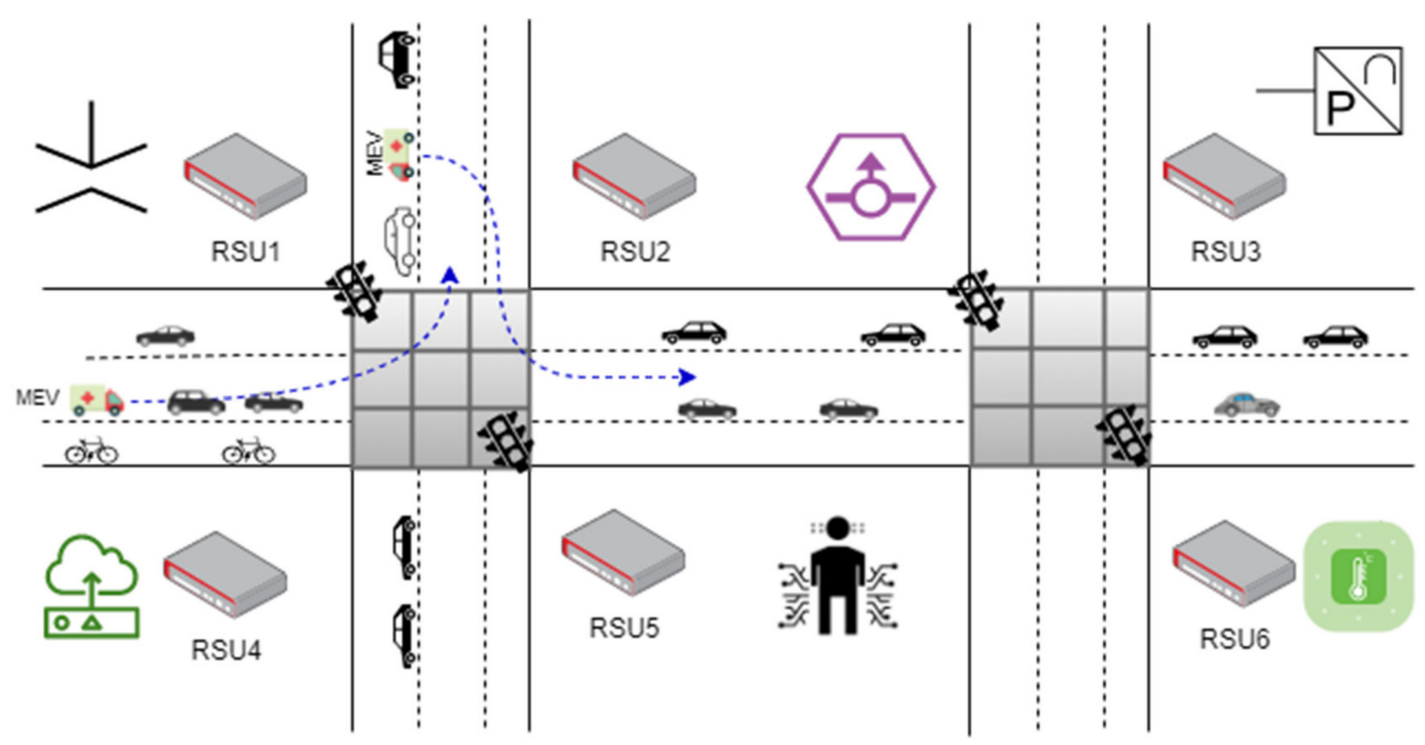

Figure 3. Case 1, mentioned in Algorithm 1 (when both vehicles have the same priorities).

Figure 4 models the situation in which two EVs, FEV and MEV on junction K1, and $\mathrm{PEV}$ and FEV on junction K2, are coming from varying directions and cannot cross simultaneously. In such a situation, the decision will be taken based on the process mentioned in Algorithm 2. The detailed working of both algorithms is also shown in the flow chart of Figure 5, where VAT refers to vehicle arrival time.

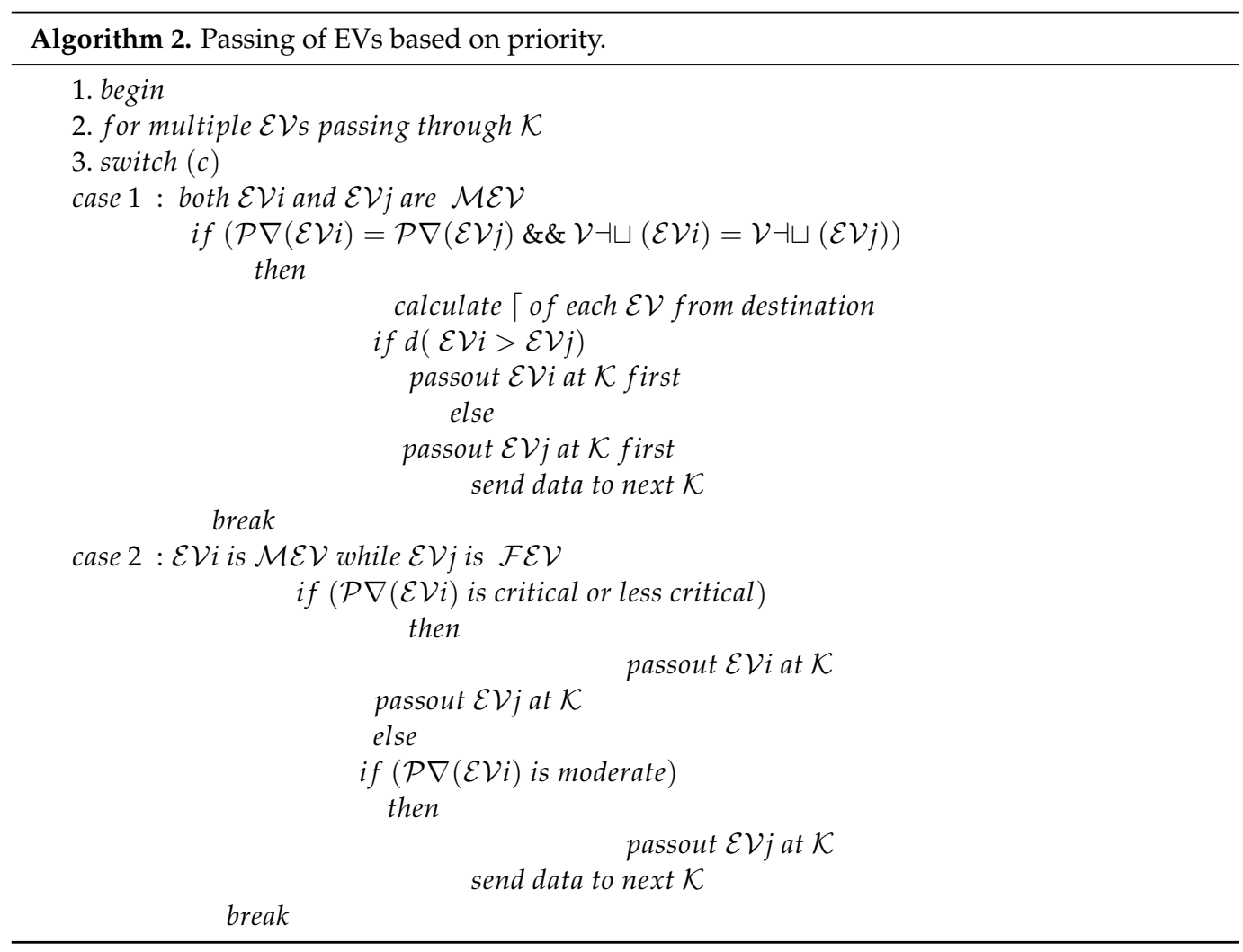


case $3: \mathcal{E} \mathcal{V}$ i is $\mathcal{M E V}$ while $\mathcal{E} \mathcal{V} j$ is $\mathcal{L} \mathcal{E} V$

if $(\mathcal{P} \nabla(\mathcal{E} \mathcal{V} i)$ is critical or less critical $)$

then

passout $\mathcal{E} \mathcal{V} j$ at $\mathcal{K}$

passout $\mathcal{E}$ Vi at $\mathcal{K}$

send data to next $\mathcal{K}$

else

if $(\mathcal{P} \nabla(\mathcal{E} \mathcal{V} i)$ is moderate $)$

then

passout $\mathcal{E} \mathcal{V} j$ at $\mathcal{K}$

send data to next $\mathcal{K}$

break

4. Resume normal traffic

5. end

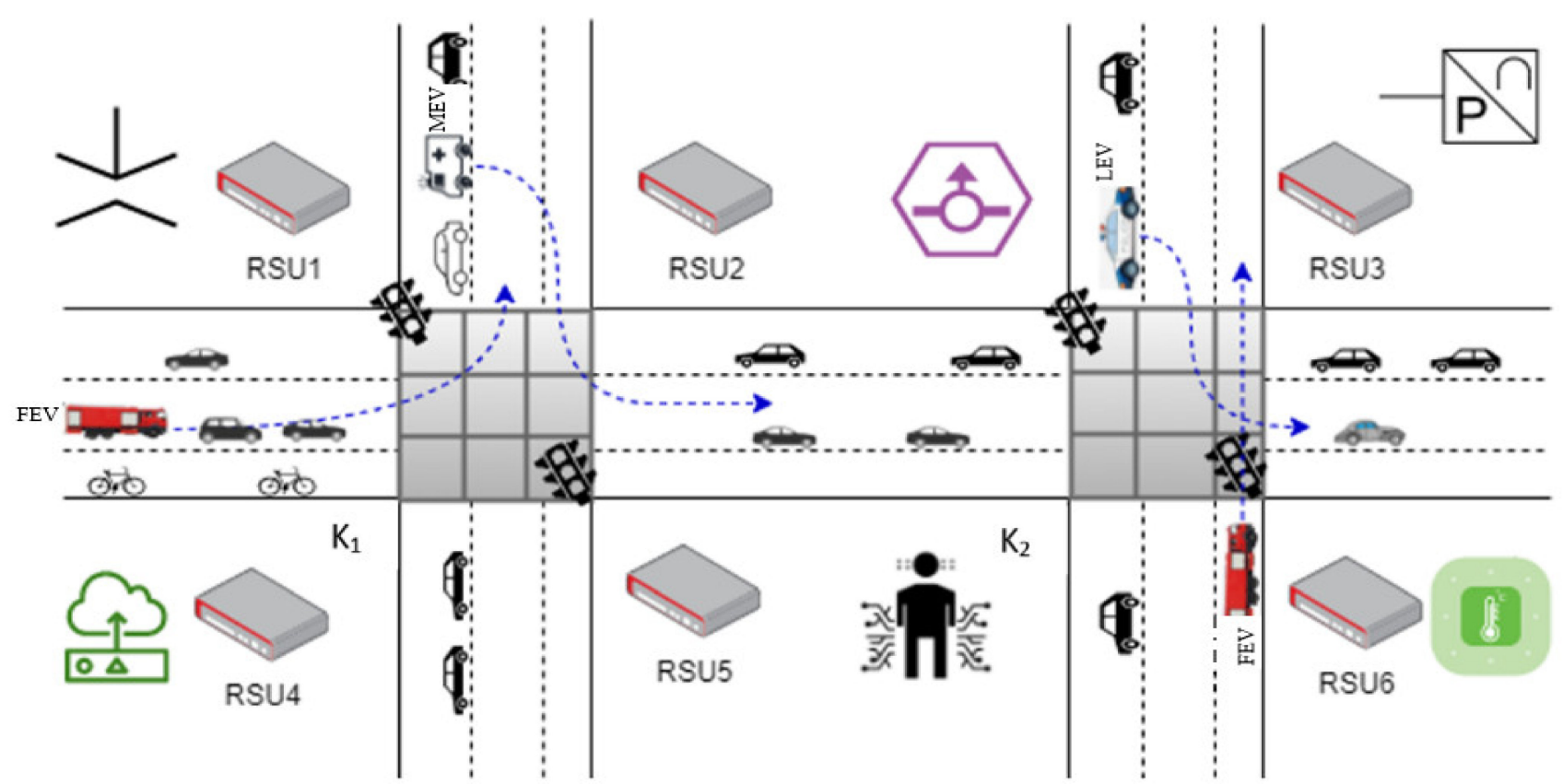

Figure 4. Case 2, mentioned in Algorithm 1 (when both vehicles have the same priorities). 


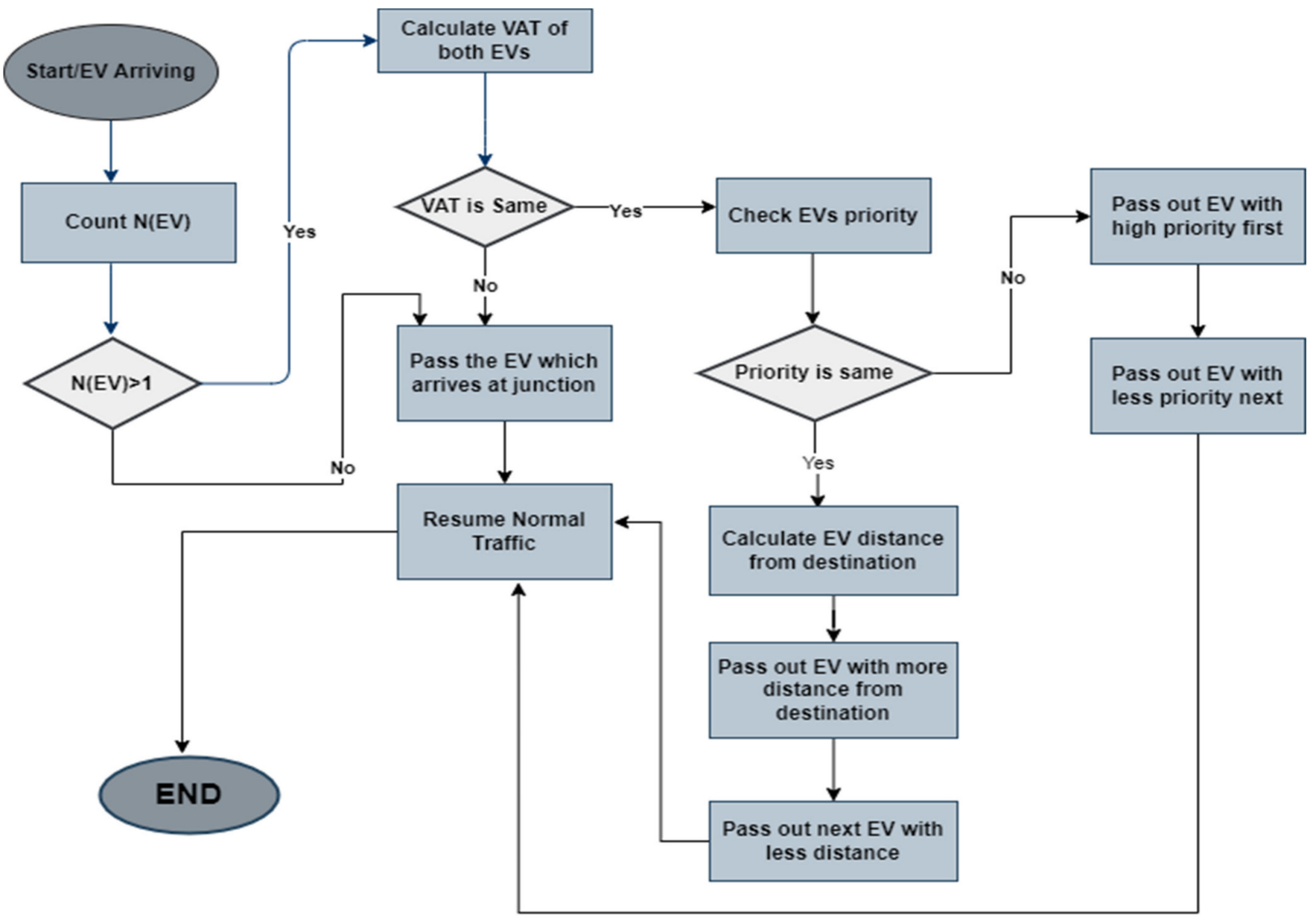

Figure 5. Working of EVMS.

\section{Mathematical Modeling of EVMS}

It is essential to investigate the traffic at the intersection in order to pass the EV quickly and preserve social order. It is practical to examine the traffic flow of intersections since the capacity of a junction directly impacts the efficiency of a road network. Analysis of the traffic conditions of junctions was carried out by setting up a mathematical model and applying it to the values of road statistics. Below we describe the details of the mathematical model. Table 3 shows the symbols and notations used throughout the paper.

Table 3. Symbols and notations used.

\begin{tabular}{cccc}
\hline Symbols & Used for & Symbols & Used for \\
\hline$v l$ & Velocity & $\mathcal{A}$ & Time taken in adjusting SL traffic \\
$\overline{v l}$ & Average velocity & $\mathbb{S}$ & Time taken in signal switching \\
$\alpha$ & Arrival rate of EV & $\mathcal{T}$ & Total time needed to adjust and pass EV \\
$t_{p}$ & Time taken to entertain an EV & $\Delta \mathbf{x}$ & Change in displacement \\
$W v$ & Waiting time for normal vehicles & $u$ & Initial velocity \\
$\rho$ & Performance parameters & $\partial$ & Acceleration \\
$\mathcal{M}$ & Time taken by normal vehicle to move to SL & $t$ & Time \\
$m / s$ & Meter per second & $m / s^{2}$ & Meter per second squared \\
$n$ & Normal vehicles on the road & $t_{n}$ & Time taken to entertain normal vehicles \\
\hline
\end{tabular}

To determine the precise moment of an EV's arrival at a junction, the distance between the EV and the intersection must be calculated. Furthermore, when there are multiple EVs with the same priority on a junction, the distance to the destination will aid in the 
prioritization of the EVs. As a result, the distance calculation is a key aspect of the EVMS. The distance from an EV to an intersection in the EVMS is calculated using the three most commonly used techniques of distance calculation, named Euclidean distance (ED), Canberra distance (CD), and Manhattan distance (MD). The formulas for the calculation of ED, CD, and MD are given in Equations (3)-(5), respectively. The distance from an EV to its destination is calculated by computing the real length of the route to the destination using a map distance calculator. Further, the symbols used in the mathematical model are mentioned in Table 3. The steps followed for this mathematical model are mentioned in Figure 6.

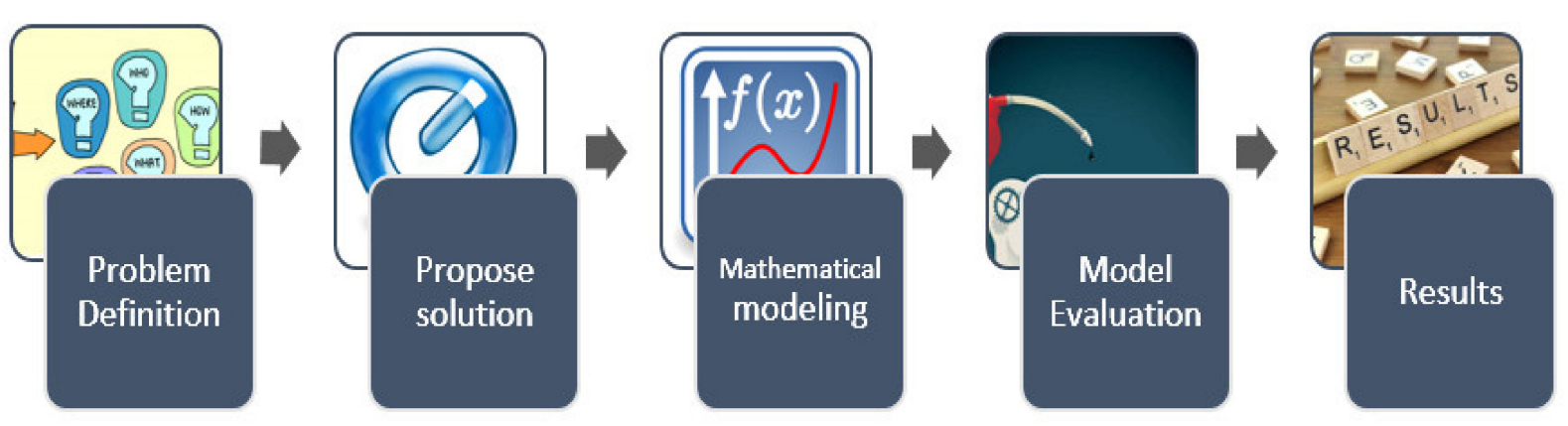

Figure 6. Steps of Mathematical modeling to validate the proposed model.

ED formula is used to compute the distance between two or more points $[35,36]$, as given in Equation (3). Let $\mathrm{a}=\left(\mathrm{x}_{1}, \mathrm{y}_{1}\right)$ and $\mathrm{b}=\left(\mathrm{x}_{2}, \mathrm{y}_{2}\right)$ be two points on a plane, then the ED between two points will be calculated as shown in Equation (3).

$$
\mathrm{ED}=\sqrt{\left(\mathrm{x}_{2}-\mathrm{x}_{1}\right)^{2}+\left(\mathrm{y}_{2}-\mathrm{y}_{1}\right)^{2}}
$$

In the EVMS, EVs will be equipped with GPS that will calculate the latitude and longitude (L\&L) values to determine the location of a vehicle. The distance from the intersection will be calculated by using the L\&L of the EV and intersection.

The CD distance is a weighted variation of the MD that is often used for data that is dispersed around a point of origin $[37,38]$. The formula for calculating CD by using the above-mentioned two coordinates is as given in Equation (4).

$$
C D=\frac{\left|x_{1}-y_{1}\right|}{\left|x_{1}\right|+\left|y_{1}\right|}+\frac{\left|x_{2}-y_{2}\right|}{\left|x_{2}\right|+\left|y_{2}\right|}
$$

The MD between two points is calculated by taking the absolute sum of the differences between the coordinates $[39,40]$. The formula for calculating MD by using the abovementioned two coordinates is as given in Equation (5).

$$
\mathrm{MD}=\left|\mathrm{x}_{1}-\mathrm{y}_{1}\right|+\left|\mathrm{x}_{2}-\mathrm{y}_{2}\right|
$$

As the vehicles do not follow the same speed on the road due to congestion on the road and other traffic-related issues, instead of speed, the velocity of EVs will be calculated $[41,42]$ using the general formulae of velocity as shown in Equation (6). Let $v l$ represent velocity, then average velocity can be computed as

$$
\overline{v l}=\frac{\Delta \mathrm{x}}{\Delta \mathrm{t}}
$$

where $\Delta \mathrm{x}$ is displacement while $\Delta \mathrm{t}$ represents the change in time. 
The performance parameter of EVs will be calculated by using the formula of Equation (7).

$$
\rho(\mathrm{EV})=\frac{\alpha}{t_{p}}
$$

The average number of EVs on the road can be measured using the formula mentioned in Equation (8), where the average number of EVs is equal to the average number of EVs in the line plus those who are being served.

$$
\operatorname{Avg}\left(\mathrm{EV}_{i}\right)=\frac{\alpha}{\alpha-t_{p}}
$$

The aim of the EVMS is not only to pass the EV efficiently but to minimize the average waiting time for the normal vehicles on the road. The waiting time for normal vehicles on the road will be measured using the formula mentioned in Equation (9).

$$
W v=\frac{n}{n\left(n-t_{p}\right)}
$$

On the arrival of an EV at an intersection, normal traffic moves towards the SL to vacate space for the $\mathrm{EV}$, and the red light is turned to green. The whole time it takes to vacate space for the EV and pass the signal onto the EV can be measured using Equation (10).

$$
\mathcal{T} \mathcal{T}=f(\mathcal{M}, \mathcal{A}, \mathcal{S})
$$

The objective function in our case will be to minimize $T T$ and $W v$; thus, the objective function in our case will be as mentioned in Equations (11) and (12).

$$
\begin{aligned}
& \text { Objective function1 }(\mathrm{OBF} 1)=\operatorname{Minimize}(\mathcal{T} \mathcal{T}) \\
& \text { Objective function2 }(\mathrm{OBF} 2)=\operatorname{Minimize}(W v)
\end{aligned}
$$

In the case of OBF1, there are three determinants of $\mathcal{T} \mathcal{T}$ as mentioned in Equation (10), the individual impact of each determinant can be found using the formulas mentioned in Equations (13)-(15).

The individual impact of each determinant can be found by taking the partial derivatives of Equation (10) as given in Equations (13) to (15).

$$
\begin{aligned}
\frac{\partial}{\partial \mathcal{M}}(T T) & =\frac{\partial}{\partial \mathcal{M}}(\mathcal{M})+\frac{\partial}{\partial \mathcal{M}}(\mathcal{A})+\frac{\partial}{\partial \mathcal{M}}(\mathcal{S})+\varepsilon \\
\frac{\partial}{\partial \mathcal{A}}(T T) & =\frac{\partial}{\partial \mathcal{A}}(\mathcal{M})+\frac{\partial}{\partial \mathcal{A}}(\mathcal{A})+\frac{\partial}{\partial \mathcal{A}}(\mathcal{S})+\varepsilon \\
\frac{\partial}{\partial \mathcal{S}}(T T) & =\frac{\partial}{\partial \mathcal{S}}(\mathcal{M})+\frac{\partial}{\partial \mathcal{S}}(\mathcal{A})+\frac{\partial}{\partial \mathcal{S}}(\mathcal{S})+\varepsilon
\end{aligned}
$$

In the same way, the determinant of average weighting times for normal vehicles and their impact can be found in Equations (16) and (17).

$$
\begin{aligned}
W_{a} & =\frac{\alpha\left(\alpha-t_{p}\right) \frac{\partial}{\partial \alpha}(\alpha)-\alpha \frac{\partial}{\partial \alpha}\left(\alpha\left(\alpha-t_{p}\right)\right.}{\left[\alpha\left(\alpha-t_{p}\right)\right]^{2}} \\
W_{t_{p}} & =\frac{\alpha\left(\alpha-t_{p}\right) \frac{\partial}{\partial t_{p}}(\alpha)-\alpha \frac{\partial}{\partial t_{p}}\left(\alpha\left(\alpha-t_{p}\right)\right.}{\left[\alpha\left(\alpha-t_{p}\right)\right]^{2}}
\end{aligned}
$$

\subsection{Data Analysis and Results}

This section will evaluate the above mathematical model with the help of data. We assume the following: 
- $\quad$ Each signal remains green for $30 \mathrm{~s}$, yellow for $10 \mathrm{~s}$, and red for $30 \mathrm{~s}$.

- The traffic at the intersection comes from four directions (east, west, north, south).

- $\quad$ EV transfers its data to the cloud through built-in IoT sensors.

- Control unit fetches EV data and acts accordingly.

- The time to adjust normal traffic to SL to vacate space for EV is assumed to be $3 \mathrm{~s}$.

- The average time to entertain a normal vehicle is $15 \mathrm{~s}$.

\subsubsection{Case 1: There Is Only One EV}

Let's evaluate the above parameters by using the data mentioned in Table 4 and assuming that only one EV is approaching the intersection. The control unit fetches EV coordinates from the cloud and calculates the distance of the EV from the intersection to know the expected arrival time for the EV.

Table 4. Road statistics (case 1).

\begin{tabular}{lll}
\hline Parameters & Values & Source \\
\hline Number of normal Lanes & 3 & RSU \\
Vehicle accumulated & 14 & RSU \\
SL status & Moderately occupied & RSU \\
Signal status while EV arrives & Red & Control unit \\
EV source coordinates & $29.989808,40.229722$ & GPS \\
Intersection coordinates & $29.977561,40.214250$ & RSU \\
EV speed & $27 \mathrm{~m} / \mathrm{s}$ & IoT sensor \\
Signal switching time & $2 \mathrm{~s}$ & RSU \\
\hline
\end{tabular}

The distance is calculated as below

$$
\begin{gathered}
\left(\mathrm{X}_{1}, \mathrm{Y}_{1}\right)=(29.989808,40.229722) \\
\left(\mathrm{X}_{2}, \mathrm{Y}_{2}\right)=(29.977561,40.21425) \\
d=\sqrt{(29.977561-29.989808)^{2}+(40.21425-40.229722)^{2}} \\
d=0.0197
\end{gathered}
$$

The distance can also be calculated using the CD or MD method. Once the distance is known, the velocity of the EV will be calculated to know the exact arrival time, the reason for calculating velocity instead of speed is that speed varies with regards to congestion and other road situations. Velocity will be calculated by an IoT-based velocity sensor using distance covered. To evaluate the performance measure of the $\mathrm{EV}$, the performance parameter will be calculated using the formula mentioned in Equation (7). In our case, the value of $\alpha$ is 1 as there is only one EV. The value of $t_{p}$ is the sum of $\mathcal{A}$ and $\mathbb{S}$, which is equal to 5 in our case, so the performance parameter will be calculated as

$$
\rho(\mathrm{EV})=\frac{\alpha}{t_{p}}=\frac{1}{5}=0.2
$$

For normal and stable systems, the value of $t_{p}$ will always exceed the arrival rate; therefore, the value of $\rho(\mathrm{EV})$ will always be less than 1 . The $W v$ will be calculated by using the formula of Equation (9), as follows:

$$
W v=\frac{n}{n\left(n-t_{n}\right)}=\frac{16}{16(16-15)}=\frac{16}{16}=1
$$

\subsubsection{Case 2: There Are Two EVs with the Same Priority}

By taking the same assumptions as above and the data in Table 5, we handle the situation of multiple EVs arriving at the same intersection at the same time with the same priority. In this case, the distance between the coordinates of the intersection and EV 
destination will be calculated for both EVs. The EV that is further from the destination will be given priority, as shown below.

Table 5. Road Statistics (Case 2).

\begin{tabular}{lll}
\hline Parameters & Values & Source \\
\hline Signal status while EVs arrives & Red & Control unit \\
Intersection coordinates & $29.977573,40.214200$ & GPS \\
EV1 Destination address & Address & Google map \\
EV2 Destination address & Address & Google map \\
EV1 priority & High & IoT sensor \\
EV2 Priority & High & IoT sensor \\
\hline
\end{tabular}

Let $d_{1}$ be the distance of EV1 from the intersection to its destination and $d_{2}$ be the distance of EV2 from the intersection to its destination. The destination address of both EVs will be given as an input to the map distance calculator. It will calculate the distance of EV1 and EV2 from their destinations.

If $d_{1}>d_{2}$, then EV1 will pass from the intersection first, otherwise EV2 will pass from the intersection.

\subsubsection{Case 3: There Are Two EVs with Varying Priorities}

In this scenario, the decision of passing EV will be based on the priority of the EV. IoT sensors will send the data of EV to the cloud, which will include the speed of the vehicle, velocity, priority, and destination address. The control unit will use this data to make decisions.

\section{Discussion}

Traffic congestion is a common problem in urban areas due to excessive population growth and the movement of people towards urban areas. This congestion creates problems for normal traffic as well as for pedestrians. However, one of the key challenges faced due to congestion is the passing of EVs on intersections during peak congestion hours. EVs sometimes carry critical patients or move to provide life safety and protection to people. The delay in passing EVs sometimes leads to fatal consequences. To overcome this issue, an EVMS is proposed based on modern cutting-edge technologies for the early transmission of EVs' information to the traffic control unit to take timely action. The EVMS in this study provides the idea of introducing an SL on congested roads to accommodate traffic in case of EV arrival. This SL will be used by cyclists and motorcyclists in normal conditions and will be used to adjust normal traffic flow in case of an EV on the road. Two algorithms are also proposed in this study to discuss the various cases of EVs, including only one EV on the junction, more than one EV on the junction with the same priority, and more than one $\mathrm{EV}$ on the junction with varying priorities.

The EVMS categorized EVs into three main types, namely medical EVs (ambulances), firefighting EVs, and law-enforcement EVs. The priority of these EVs is mentioned in Equations (1) and (2). The medical EV is further categorized into three levels based on the criticality of the patient inside: highly critical, less critical, and moderate. This priority helps the control unit in decision making while there is more than one EV at the intersection at the same time. According to the EVMS, all three EV types are equipped with GPS and IoT sensors to collect EV information. This collected information is sent to the cloud through IoT sensors using a 5G network. The control unit fetches the EV data from the cloud and makes a decision accordingly. In the case of a single EV at the intersection, the control unit turns the signal green when the EV reaches the intersection. In the case of more than one EV from varying directions at the intersection, the decision is either based on the priority of the EV or its distance from the destination. When both EVs have different priorities, the control unit passes the EV with high priority first. In the case of the same priority, the 
distance of $\mathrm{EV}$ from the destination is calculated and the EV with more distance from the destination is given priority.

To evaluate the proposed methodology, we have proposed various mathematical equations to calculate the EV parameters, including distance, velocity, performance parameters, the average number of EVs on the roads, and the effect of various factors. The proposed methodology is different from existing studies in different ways; firstly, existing studies do not consider the issue of multiple EVs with the same priority [43]. Secondly, they just assign a high priority to medical EVs without classifying it into various levels [4]. Table 6 compares the proposed system with a few existing studies on EVs. It shows that the proposed system provides a precise mechanism for handling EVs.

Table 6. Comparison with existing studies.

\begin{tabular}{cccc}
\hline Paper & Single EV & $\begin{array}{c}\text { Two EVs with the } \\
\text { Same Priority }\end{array}$ & $\begin{array}{c}\text { Two EVs with } \\
\text { Varying Priority }\end{array}$ \\
\hline$[4]$ & Yes & No & Yes \\
{$[10]$} & Yes & No & Yes \\
{$[43]$} & Yes & No & No \\
EVMS & Yes & Yes & Yes \\
\hline
\end{tabular}

\section{Conclusions and Future Work}

The passing of EVs on intersections especially in urban areas is a key challenge due to traffic congestion. Various solutions address the problem of traffic congestion, but the passing of EVs with minimal impact on normal traffic is still a challenge. To overcome this issue, an EVMS has been proposed in this research; the proposed EVMS uses modern cutting-edge technologies for getting timely information about EVs. According to EVMS, EVs are equipped with GPS and IoT sensors, these sensors fetch EV data and transmit it to the cloud using 5G Internet service. The traffic management unit collects this data from the cloud and makes decisions accordingly. Two algorithms of passing single and multiple EVs with the same and different priorities have been developed. The EVMS is evaluated using mathematical modeling, and results suggest that the proposed system outperforms in the case of single and multiple EVs.

We are planning to apply the EVMS on real-time traffic data for a better evaluation in the future. We are also planning to strengthen this EVMS by adding more cutting-edge technologies to address the security and safety issues of the autonomous traffic system as well.

Author Contributions: Conceptualization, N.Z.J.; Data curation, M.H.; Formal analysis, N.Z.J.; Funding acquisition, M.F.A.; Investigation, M.H. and M.F.A.; Methodology, M.H.; Project administration, N.Z.J.; Resources, M.F.A.; Software, M.F.A.; Writing—original draft, M.H.; Writing—review \& editing, N.Z.J. All authors have read and agreed to the published version of the manuscript.

Funding: This work was funded by the Deanship of Scientific Research at Jouf University under grant No (DSR-2021-02-0327).

Data Availability Statement: Data will be available upon request.

Conflicts of Interest: The authors declare no conflict of interest.

\section{References}

1. Nieuwenhuijsen, M.J. Urban and transport planning pathways to carbon neutral, liveable and healthy cities; A review of the current evidence. Environ. Int. 2020, 140, 105661. [CrossRef] [PubMed]

2. AlAttar, M.; Al-Mutairi, N. Quantification of time and fuel losses due to daily traffic congestion in Kuwait. Int. J. Crashworthiness 2021, 26, 258-269. [CrossRef]

3. Younes, M.B.; Boukerche, A. An efficient dynamic traffic light scheduling algorithm considering emergency vehicles for intelligent transportation systems. Wirel. Netw. 2018, 24, 2451-2463. [CrossRef]

4. Sumi, L.; Ranga, V. Intelligent traffic management system for prioritizing emergency vehicles in a smart city. Int. J. Eng. 2018, 31, 278-283. 
5. Lu, Q.; Kim, K.-D. A genetic algorithm approach for expedited crossing of emergency vehicles in connected and autonomous intersection traffic. J. Adv. Transp. 2017, 2017, 1-15. [CrossRef]

6. Bhate, S.V.; Kulkarni, P.V.; Lagad, S.D.; Shinde, M.D.; Patil, S. IoT based intelligent traffic signal system for emergency vehicles In Proceedings of the 2018 Second International Conference on Inventive Communication and Computational Technologies (ICICCT), Coimbatore, India, 20-21 April 2018.

7. Traffic Safety Facts Annual Report Tables. Available online: https://cdan.nhtsa.gov/tsftables/tsfar.htm (accessed on 6 January 2021).

8. Watanabe, B.L.; Patterson, G.S.; Kempema, J.M.; Magallanes, O.; Brown, L.H. Is use of warning lights and sirens associated with increased risk of ambulance crashes? A contemporary analysis using National EMS Information System (NEMSIS) data. Ann. Emerg. Med. 2019, 74, 101-109. [CrossRef] [PubMed]

9. Naik, T.; Roopalakshmi, R.; Ravi, N.D.; Jain, P.; Sowmya, B.H.; Manichandra. RFID-based smart traffic control framework for emergency vehicles. In Proceedings of the 2018 Second International Conference on Inventive Communication and Computational Technologies (ICICCT), Coimbatore, India, 20-21 April 2018.

10. Nellore, K.; Hancke, G.P. Traffic management for emergency vehicle priority based on visual sensing. Sensors 2016, 16, 1892. [CrossRef] [PubMed]

11. Chowdhury, A. Priority based and secured traffic management system for emergency vehicle using IoT. In Proceedings of the 2016 International Conference on Engineering \& MIS (ICEMIS), Agadir, Morocco, 22-24 September 2016.

12. Karmakar, G.; Chowdhury, A.; Kamruzzaman, J.; Gondal, I. A smart priority based traffic control system for emergency vehicles. IEEE Sens. J. 2020, 21, 15849-15858. [CrossRef]

13. Tammishetty, S.; Ragunathan, T.; Battula, S.K.; Rani, B.V.; Ravi Babu, P.; Nagireddy, R.; Jorika, V.; Reddy, V.M. IOT-based traffic signal control technique for helping emergency vehicles. In Proceedings of the First International Conference on Computational Intelligence and Informatics; Springer: Berlin/Heidelberg, Germany, 2017.

14. Amir, S.; Kamal, M.S.; Khan, S.S.; Salam, K.M.A. PLC based traffic control system with emergency vehicle detection and management. In Proceedings of the 2017 International Conference on Intelligent Computing, Instrumentation and Control Technologies (ICICICT), Kerala, India, 6-7 July 2017.

15. Khan, A.; Ullah, F.; Kaleem, Z.; Rahman, S.U.; Anwar, H.; Cho, Y.-Z. EVP-STC: Emergency vehicle priority and self-organising traffic control at intersections using Internet-of-things platform. IEEE Access 2018, 6, 68242-68254. [CrossRef]

16. Avatefipour, O.; Sadry, F. Traffic management system using IoT technology-A comparative review. In Proceedings of the 2018 IEEE International Conference on Electro/Information Technology (EIT), Rochester, MI, USA, 3-5 May 2018.

17. Ghosal, S.; Chatterjee, T. Controlling Emergency Vehicles During Road Congestion-A Survey and Solution. In Computational Intelligence in Pattern Recognition; Springer: Singapore, 2020; pp. 529-538.

18. Awan, K.A.; Din, I.U.; Almogren, A.; Kim, B.S.; Altameem, A. vTrust: An IoT-Enabled Trust-Based Secure Wireless Energy Sharing Mechanism for Vehicular Ad Hoc Networks. Sensors 2021, 21, 7363. [CrossRef]

19. Humayun, M.; Jhanjhi, N.; Hamid, B.; Ahmed, G. Emerging smart logistics and transportation using IoT and blockchain. IEEE Internet Things Mag. 2020, 3, 58-62. [CrossRef]

20. Humayun, M.; Jhanjhi, N.Z.; Alamri, M.Z.; Khan, A. Smart Cities and Digital Governance. In Employing Recent Technologies for Improved Digital Governance; IGI Global: Hershey, PA, USA, 2020; pp. 87-106.

21. Jadoon, G.; Din, I.U.; Almogren, A.; Almajed, H. Smart and agile manufacturing framework, a case study for automotive industry. Energies 2020, 13, 5766. [CrossRef]

22. Zeng, Z.; Yi, W.; Wang, S.; Qu, X. Emergency vehicle routing in urban road networks with multistakeholder cooperation. J. Transp. Eng. Part A Syst. 2021, 147, 04021064. [CrossRef]

23. Oubbati, O.S.; Lakas, A.; Lorenz, P.; Atiquzzaman, M.; Jamalipour, A. Leveraging communicating UAVs for emergency vehicle guidance in urban areas. IEEE Trans. Emerg. Top. Comput. 2021, 9, 1070-1082. [CrossRef]

24. Wu, J.; Kulcsár, B.; Ahn, S.; Qu, X. Emergency vehicle lane pre-clearing: From microscopic cooperation to routing decision making Transp. Res. Part B Methodol. 2020, 141, 223-239. [CrossRef]

25. Li, B.; Zhang, Y.; Jia, N.; Zhou, C.; Ge, Y.; Liu, H.; Meng, W.; Ji, C. Paving green passage for emergency vehicle in heavy traffic: Real-time motion planning under the connected and automated vehicles environment. In Proceedings of the 2017 IEEE International Symposium on Safety, Security and Rescue Robotics (SSRR), Shanghai, China, 11-13 October 2017.

26. Akabane, A.T.; Immich, R.; Bittencourt, L.F.; Madeira, E.R.; Villas, L.A. Towards a distributed and infrastructure-less vehicular traffic management system. Comput. Commun. 2020, 151, 306-319. [CrossRef]

27. Fogue, M.; Sanguesa, J.A.; Martinez, F.J.; Marquez-Barja, J.M. Improving roadside unit deployment in vehicular networks by exploiting genetic algorithms. Appl. Sci. 2018, 8, 86. [CrossRef]

28. Fakirah, M.; Leng, S.; Chen, X.; Zhou, J. Visible light communication-based traffic control of autonomous vehicles at multi-lane roundabouts. EURASIP J. Wirel. Commun. Netw. 2020, 2020, 1-14. [CrossRef]

29. Ullah, A.; Azeem, M.; Ashraf, H.; Alaboudi, A.A.; Humayun, M.; Jhanjhi, N. Secure healthcare data aggregation and transmission in IoT-A survey. IEEE Access 2021, 9, 16849-16865. [CrossRef]

30. Humayun, M. Role of emerging IoT big data and cloud computing for real time application. Int. J. Adv. Comput. Sci. Appl. 2020, 11,1-13. [CrossRef] 
31. Alayda, S.; Almowaysher, N.; Humayun, M.; Jhanjhi, N. A Novel Hybrid Approach for Access Control in Cloud Computing. Int. J. Eng. Res. Technol. 2020, 13, 3404-3414. [CrossRef]

32. Humayun, M.; Jhanjhi, N.; Alruwaili, M.; Amalathas, S.S.; Balasubramanian, V.; Selvaraj, B. Privacy protection and energy optimization for 5G-aided industrial Internet of Things. IEEE Access 2020, 8, 183665-183677. [CrossRef]

33. Humayun, M.; Hamid, B.; Jhanjhi, N.; Suseendran, G.; Talib, M.N. 5G Network Security Issues, Challenges, Opportunities and Future Directions: A Survey. In Journal of Physics: Conference Series; IOP Publishing: Bristol, UK, 2021.

34. Créput, J.-C.; Hajjam, A.; Koukam, A.; Kuhn, O. Dynamic vehicle routing problem for medical emergency management. In Self Organizing Maps-Applications and Novel Algorithm Design; Intechopen: London, UK, 2011; pp. 233-250.

35. Mesquita, D.P.; Gomes, J.P.; Junior, A.H.S.; Nobre, J. Euclidean distance estimation in incomplete datasets. Neurocomputing 2017, 248, 11-18. [CrossRef]

36. Tabaghi, P.; Dokmanić, I.; Vetterli, M. Kinetic Euclidean distance matrices. IEEE Trans. Signal Process. 2019, 68, 452-465. [CrossRef]

37. Gultom, S.; Sriadhi, S.; Martiano, M.; Simarmata, J. Comparison analysis of K-means and K-medoid with Ecluidience distance algorithm, Chanberra distance, and Chebyshev distance for big data clustering. In IOP Conference Series: Materials Science and Engineering; IOP Publishing: Bristol, UK, 2018.

38. Santosh, M.; Sharma, A. A proposed framework for emotion recognition using Canberra distance classifier. J. Comput. Theor. Nanosci. 2019, 16, 3778-3782. [CrossRef]

39. Lubis, A.R.; Lubis, M. Optimization of distance formula in K-Nearest Neighbor method. Bull. Electr. Eng. Inform. 2020, 9, 326-338. [CrossRef]

40. Sitompul, O.; Nababan, E. Measuring the accuracy of simple evolving connectionist system with varying distance formulas. In Journal of Physics: Conference Series; IOP Publishing: Bristol, UK, 2017.

41. Li, L.; Coskun, S.; Zhang, F.; Langari, R.; Xi, J. Energy management of hybrid electric vehicle using vehicle lateral dynamic in velocity prediction. IEEE Trans. Veh. Technol. 2019, 68, 3279-3293. [CrossRef]

42. Borowczyk, A.; Nguyen, D.-T.; Nguyen, A.P.-V.; Nguyen, D.Q.; Saussié, D.; Le Ny, J. Autonomous landing of a multirotor micro air vehicle on a high velocity ground vehicle. Ifac-Papersonline 2017, 50, 10488-10494. [CrossRef]

43. González, C.L.; Pulido, J.J.; Alberola, J.M.; Julian, V.; Niño, L.F. Autonomous Distributed Intersection Management for Emergency Vehicles at Intersections. In Practical Applications of Agents and Multi-Agent Systems; Springer: Berlin/Heidelberg, Germany, 2021. 